\title{
CULTURAL ADAPTATION OF ERASMUS STUDENTS IN LATVIA AND HOST UNIVERSITY RESPONSIBILITY
}

\author{
Velga Vevere $^{1}$, Consuelo Resentini ${ }^{2}$, Marcos Garcia Alfaya ${ }^{3}$, Angel Muniz Mejuto ${ }^{4}$ \\ ${ }^{I}$ The University College of Economics and Culture,Latvia,velga.vevere@gmail.com \\ ${ }^{2}$ University of Milano-Bicocca, Italy,c.resentini1@campus.unimib.it \\ ${ }^{3}$ University of Vigo, Spain, marcos.garcia.alfaya@hotmail.com \\ ${ }^{4}$ University of Vigo, Spain, munizmejutoangel@gmail.com
}

\begin{abstract}
Internationalisation of education and student mobility (incoming and outgoing) has become a significant factor in the sphere of higher education. These processes lead to interaction between local students and exchange students, as well as between exchange students and host universities. Being in the foreign country for a certain period (one or two semesters) requires some cultural and social adaptation that could or could not be problematic for various reasons. In order to maximise benefits for the exchange students and host universities, it is important to identify existing problems and to offer possible solutions. The aim of the current paper is to research the critical aspects of cultural adaptation process of ERASMUS students in Latvia. The international group that consists of a professor of the University College of Economics and Culture and three exchange students from Italy and Spain carried out the research. The empirical methods used were the following: a survey of ERASMUS students (non-probability purposive sampling) and semi-structured interviews with the host university ERASMUS coordinators. The data processing methods were the descriptive statistics as well as the thematic content analysis. On the basis of critical issues identified during the research process, the authors worked a set of practical solutions aimed at the host institutions.
\end{abstract}

Keywords: internationalisation of education; student mobility; cultural adaptation; social adaptation; university social responsibility

JEL Classification: I23, M14

\section{Introduction}

Institutions of higher education face multiple challenges in the contemporary world, such as commercialisation of education, market forces, development of technologies and globalisation. The latter factor involves the student and staff mobility, the growing number of full-time international students, the joint study programmes and the need for training of the academic and administrative staff. However, many international students face challenges as they study outside of their home countries. They face social, cultural and academic obstacles, and possibly, psychological isolation. Still, the concept of internationalisation involves also matters related to cultural and intellectual exchange, human resource development, improvement of teaching quality, university reputation building and so on (Knight 2007, Altbach and Knight 2007). In addition, the process of globalisation also facilitates the internationalisation of curriculum (increasing the number of courses or even the whole programmes taught in English, e.g.). Student mobility may take several forms: longer term in order to obtain the particular degree (BA, MA and PHD), or to study for a full academic year; and shorter term (a few weeks) depending on a range of factors - the ERASMUS mobility support, the host university programmes (synchronicity and similarity with the sending institution), possibility to transfer European Credit Transfer (ECT) points and so on (Richardson and Munday 2013). Not the least, the social and cultural environment factors of the receiving country and institution are to be taken into account (Hofstede 2001, Hofstede et. al. 2010). According to the European Commission report, student mobility contributes to individuals' personal and professional development, as well as development of their foreign language skills and intercultural awareness. Students also develop their skills, such as being able to quickly adapt to changes and new situations, solving problems, working in 
teams, thinking critically, being tolerant of different views and communicating effectively (European Commission 2015). Bhandari and Blumenthal in their article "Global Student Mobility and the Twenty- First Century Silk Road: National Trends and New Directions" (Bhandari and Blumenthal 2011) pay attention to the changed drivers of the student mobility. The authors mention the following contemporary trends: growing competition for international students because they benefit the host universities in many respects (teaching and learning quality, improvement of curriculum, intercultural awareness, financial and social benefits, etc.); emerging of new mobility destinations (more players in the field of international education) - many of previous largest senders of students have become the receivers of them; growing population of virtual learning and other alternative modes of education delivery; joint and double degree programmes, consortia arrangements, twinning and curricular integration. One of the most important components of the cross-border education is students' movement away from their home countries and adaptation in the host country and host university (Varghese 2008, Gürüz 2008). Many researchers distinguish between the two concepts internationalisation at home and internationalisation abroad. The first concept refers to internationalisation processes that take place within the local university and, in most cases, signifies the ways in which the curriculum is designed to meet the needs of international students, whilst the latter one generally refers to all forms of education that go beyond the limits of political borders and include the movement of students, scholars, programmes and projects to and from different countries (Larsen 2016).

International students bring with them their home experience in learning, interacting, thinking, reasoning, as well as cooking, dining, travelling and so on. At the same time, they bring the considerable financial benefits to the host universities through their expenditures on tutoring and living expenses (Wu et al 2015). The internationalisation drivers of the higher education institutions can be classified as academic (belief that education and research have a worldwide scope) or economic (finding new sources of revenues and growth) (Hwawini 2016). In the overview of ERASMUS student mobility research, Teichler states that almost all participating students are highly satisfied with the ERASMUS experience in another European country. Many students report a substantial progress in their learning and language proficiency. Nevertheless, about $20 \%$ of the students experienced financial, administrative and accommodation problems, whilst academic problems are less frequently stated. Thus, the main challenges international students face whilst studying abroad can be divided into three large groups: the academic, the social and the cultural ones (Teichler 2004, 2007).

The current investigation is the collaborative project carried out by the professor of the University College of Economics and Culture and three ERASMUS students representing Spain and Italy. It consisted of the subsequent stages: creating the theoretical framework, formulation of research design and methodology, data processing and result interpretation. The purpose of this study is to research the critical aspects of cultural adaptation process of ERASMUS students in Latvia. The study uses the mixed approach involving the quantitative research - the ERASMUS student survey (non-probability snowball sampling) - and the qualitative one - the semi-structured interviews with ERASMUS coordinators. Data processing methods are the descriptive statistics and thematic content analysis. To reach the purpose of the study, we put forward two research questions: (1) What are the most problematic aspects of ERASMUS students' social-cultural adaptation in Latvia? (2) What are the responsibilities of host universities in ensuring international students' cultural and social adaptation?

\section{Literature Review}

In order to systematise the literature devoted to the international students' adaptation to host universities' cultural (and social) environment, we propose to use the acculturation scheme developed by Ward, Bochner and Furnham (2001). The scheme depicts the interdependency of societal and individual level variables.

- Society of origin (social, political, economic and cultural factors) and society of settlement (social, political, economic and cultural factors) influence societal level variables

- Societal and individual level variables: cross-cultural transition (life changes, intercultural contact) $\rightarrow$ stress and skills deficits $\rightarrow$ stress coping strategies and culture-specific skills 
acquisition $\rightarrow$ responses (affective, behavioural, cognitive) $\rightarrow$ outcomes (psychological, socio-cultural)

- Characteristics of the person (personality, language fluency, training and experience, cultural identity, acculturation strategies, values, reason for mobility) and characteristics of the situation (length of cultural contact, amount of intra- and inter-group contact, quality of intraand inter-group contact, cultural distance, amount of life changes, social support)

This scheme demonstrates that cross-cultural transition involves adaptive change that involves working out stress-coping strategies and acquisition of new social and cultural skills and results in psychological adjustment and socio-cultural adaptation. The individual variables are both the factors of influence (i.e. the personality traits play a prominent role in the formation of coping strategies; the situational aspects that form the background for change - the length of culture exposure, social contacts, cultural distance, etc.). All the elements in the scheme are interdependent. Thus, the theoretical background of the theme of socio-cultural adaptation falls into such broad thematic areas: (1) the role of host universities in the process of ERASMUS students' intercultural adaptation; (2) culture shock and transition difficulties, skills acquisition, stress coping strategies and final adaptation; (3) the impact factor (future employment possibilities).

Owing to the process of globalisation and the advance of transnational education, universities and colleges have to engage in the so-called 'ranking game', namely, rankings are gaining in both popularity and influence (Grewal et al 2008), generating a high interest and involvement in finding and applying strategic measures to remain competitive. The significant indicator of competitiveness, amongst others, is one of the attractions of foreign students and offers international curricula. Considering this, the international students' academic, social and cultural adaptation is a part of the university social responsibility that can be defined as the ability of the university to disseminate and implement a set of general principles and specific values through four processes - management, teaching, research and extension following ethical principles of good governance (Giuffré and Ratto 2014, Vevere 2016). Therefore, the responsibility of the host university is to ensure international students' equity treatment (protection of civil and human rights), intercultural competences (such as recognition of one's own cultural and national perspectives, an awareness and respect for other perspectives), integration of international students, opportunity to complete studies (the same rules and regulations are valid for all students - the local and the international ones), portability and continuity of funding (students on grants that cover tuition and expenses whilst studying abroad should be provided with safeguards against arbitrary withdrawal of their funding), student status, visas and formal requirements, information and quality assurance (International Student Mobility Charter). The reputation as the good host university for student mobility programmes is a significant competitive advantage because it can help to attract top students and academicians, as well as research funds and transnational partnerships. Bennett (2004) has worked out the so-called 'Developmental model of intercultural sensitivity' - a correlation between the psychosocial experience of the adjustment process and the national culture dimension. Nevertheless, it should be taken into account that the university social responsibility concept pertains also the sending institutions or home universities, as prospective participants of the mobility programme have to have some preliminary information about the host university and have to be emotionally prepared. This can be done by the means such as social media (such as the students' groups on Facebook and the host university web page), intercultural and language training. Additionally, there is phenomenon such as student self-help (students helping students) or, in other words, the ESN (the ERASMUS Student Network) that publishes 'ESN Student Guidebook' annually (Studying and Training Abroad 2015). The guidebook provides the essential information about students' rights and obligations, the necessary documents as well as the local ESN contacts.

When arriving in the place of destination (traditional placement or rather exotic one), students are immersed in the largely unknown situation - they have to interact with the functional proximity context (the academic experience they are faced with their dominant role as visiting students), especially if they are coming from very different cultural, social and academic background. That can create the situation of the culture shock. There are a great number of publications devoted to this 
problem. The Swedish anthropologist Oberg (1960) gives the classical description of the culture shock, admitting that it is precipitated by the anxiety that results from losing all our familiar signs and symbols of social intercourse. He mentions symptoms of the culture shock such as excessive concern over hygiene and eating habits, fear of physical contacts, absent-minded, far-away stare, feeling of helplessness, dependence on diaspora, many minor frustrations and refusal to acquire new habits. Other researchers (Bochner 2003, Pedersen et al 2011, Furnham and Bochner 1986, Ward et al 2001, Zhou et al 2008, Geeraert and Demoulin 2013) believe that the use of the word 'shock' places too much emphasis on the threatening circumstances of contact with novel situations, without acknowledging that such experiences may also have beneficial consequences for the participants. They propose to substitute it with several terms: 'between society culture-contact', that is, psychology of the traveller or sojourner who ventures across cultures; 'sojourner adjustment', a term expanding on the acculturation concept to apply to groups residing temporarily in foreign environments, suggests that engagement, participation, and temporary integration into the host culture may contribute to less psychological and socio-cultural difficulty whilst abroad; and 'acculturative stress'. In general, the researchers distinguish between three and five stages of the culture shock that is often depicted as the U-curve model (Oberg, 1960, Gullahorn and Gullahorn 1963, Mendenhall 1991). This model explains the emotional curve of the emotional stages the students go through during their intercultural sojourns. Beginning with a high level of optimism, students are then facing distrust and despair when the negative aspects of the culture are revealed; experiencing what is known as culture shock. In the next stage - the acculturation stage - the individual gets more and more acquainted with the new cultural medium and he starts to accept the host culture, preparing for the calm waters of the equilibrium stage of belonging. In the context of the student mobility, it is worth to mention also the phenomenon of the reverse culture shock or re-entry shock of students returning from studies overseas, sometimes described also as the W-curve model (U-curve model repeated twice over) (Gaw 2000). This term refer to the adjustments that returnees should make in order to adapt back into their own culture after experiencing a different cultural and social environment.

Finally, the third group of publications deals with the impact of the student mobility (Archer and Davidson 2008, Crossman and Clarke, 2010). The researchers stress that studying abroad could significantly increase their future employability. Thus, for example, the ERASMUS large-scale impact study demonstrates (European Commission 2014) that 'transversal skills' were identified by $92 \%$ of employers as essential to employment and subsequent career development. Yet in an another study (Bracht et al 2006), the survey of the former ERASMUS students concluded that the ERASMUS participants associated their experience of mobility with improved international competences and facilitated access to the labour market. Apart from the employability, all investigators admit the importance of developing the so-called soft-skills: intercultural communication, teamwork, team leadership, crisis management and so on.

\section{Methodology}

Research design. In order to investigate ERASMUS students' perception of their cultural and social adaptation process in Latvia, we chose the mixed methods research that comprised the quantitative research, the formalised survey of respondents, and the qualitative one, a series of semi-structured interviews with ERASMUS coordinators. The students were approached with the request to be questioned about their opinion via Internet (using the Google forms). The questionnaire was developed based on the relevant literature study; it consisted of 16 statements concerning cultural and social issues that students face whilst studying in Latvia. Each statement had five-point value varying from the answer 'strongly agree' and 'agree' to 'neither', 'disagree' and 'strongly disagree'. The ERASMUS coordinators were approached with a questionnaire consisting of 12 open-ended questions. The rationale of these interviews was to find out the key factors that influence ERASMUS students' socio-cultural adaptation in Latvia and what is being done on the part of the university.

Population sampling. Once the research design was established, it was necessary to make a decision about the sampling unit (a unit of population chosen during the sampling process; the unit should contain one or more elements describing the population) and sampling method. The respondents of the survey were chosen according to the principle to include the ERASMUS students studying in Latvia in 
the first semester of the study year 2016-2017. This procedure can be described as a non-probability purposive sampling, that is, the single-stage procedure in which sampling unit contains only one element, namely, being in Latvia as ERASMUS mobility programme participant. Altogether 87 students were surveyed. The respondents of the semi-structured interviews were the ERASMUS coordinators of three higher educational establishments (business schools), encoded as universities A, $\mathrm{B}$ and $\mathrm{C}$.

Data processing. The participants were asked to rate each statement on a five-point Likert scale. The descriptive statistics was applied to interpret data. The results were grouped according to the aspects of the research, that is, the lifestyle, the living conditions, leisure time, food and restaurant culture and interaction (communication) with the locals. After that, the comparative analysis of the results was performed. The last stage was the thematic content analysis of the interview texts with the aim to see if there is a gap in situation perception by the ERASMUS students and their host organisations.

Limitations of research. As the ERASMUS students mostly spend abroad one semester (with some exceptions), the data was gathered during the first semester of the study year 2016-2017. The questionnaire was distributed through the ERASMUS Student Network Latvia (ESN Latvia), so only those students who were engaged in the network at the time could be reached. Although the ESN Latvia Facebook page has more than 15,000 followers as of today, not all of them are incoming ERASMUS students, amongst them, there are ERASMUS alumni, both international and local. Still, we believe that the results we obtained demonstrate the overall tendency, especially if complemented with the qualitative (interview) data.

The research questions are the following: (1) What are the most problematic aspects of ERASMUS students' social-cultural adaptation in Latvia? (2) What are responsibilities of host universities in ensuring the international students' cultural and social adaptation?

\section{Results}

In the beginning of the survey, the ERASMUS students were asked to state their country of origin. The obtained data is rather of the informative character because the varying number of respondents represented the countries (Table 1).

Table 1. Distribution of ERASMUS students by the country of origin (Source: authors' compilation)

\begin{tabular}{|c|c|}
\hline Country of origin & Number of responses \\
\hline Algeria & 1 \\
\hline Azerbaijan & 1 \\
\hline Belgium & 2 \\
\hline Croatia & 2 \\
\hline Czech Republic & 2 \\
\hline France & 17 \\
\hline Germany & 1 \\
\hline Greece & 6 \\
\hline Italy & 1 \\
\hline Japan & 1 \\
\hline Lithuania & 1 \\
\hline Poland & 2 \\
\hline Portugal & \\
\hline & \\
\hline
\end{tabular}




\begin{tabular}{|c|c|}
\hline Romania & 1 \\
\hline Slovakia & 1 \\
\hline Spain & 43 \\
\hline Sweden & 3 \\
\hline Turkey & 1 \\
\hline Total number & 87 \\
\hline
\end{tabular}

This broad dispersion of answers (as high as 43 students from Spain and 17 from Germany, as low as 1 student from a number of countries, including Lithuania, Poland, Slovakia and others), in our opinion, could be explained by two main reasons. The first, two (out of four) research group members were coming from Spain so the response level from their compatriots was higher (a kind of the inner circle phenomenon); the second, because it was the Internet survey, not all students took their time and put in some effort to fill out the questionnaire.

Then students were asked to evaluate 16 statements regarding their socio-cultural experiences whilst residing in Latvia. The questions concerned the lifestyle (differences between the Latvian and the native country ones), the local living conditions (including the adaptation to the local weather), the leisure time and entertainment, the differences between food cultures and, finally, the problems in communication with locals of different age (less than 28 , between 28 and 60 , more than 60 ). Figure 1 depicts students' overall evaluation of the Latvian lifestyle, that is, the general impression of the host country (abbreviations: sd, strongly disagree; $d$, disagree; $n$, neither; a, agree; sa, strongly agree).

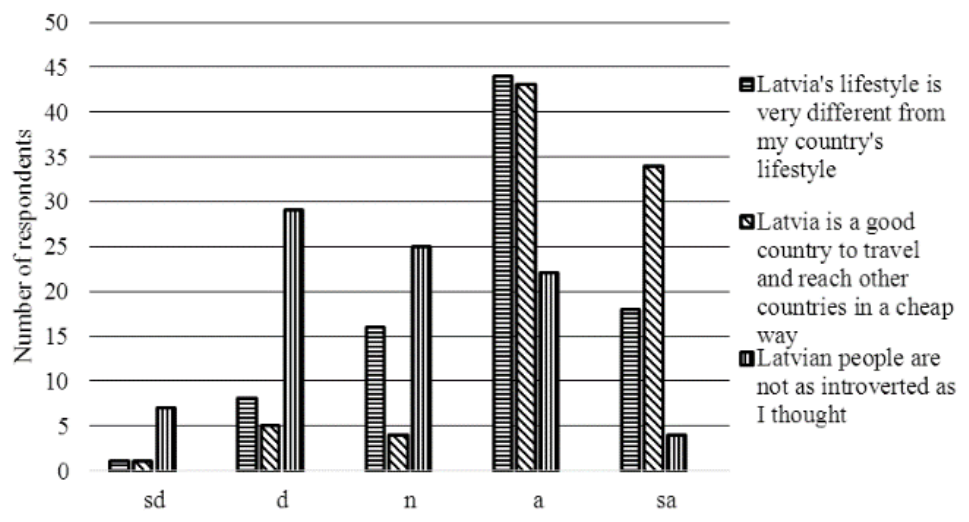

Fig. 1. Attitude to the Latvia's people lifestyle (Source: authors' compilation)

As we can see from Fig. 1, the ERASMUS students in their majority admit that the Latvian lifestyle is quite different from the one on their home countries (out of total numer of all respondents, 44 agreed and 18 strongly agreed to the statement), it pertains intercultural communication and interaction aspects such as keeping distance, greetings, speaking patterns, eye contacts as well as all cultural and social environment. This, of course, is not surprising, because arrival for a shorter or longer stay in any foreign country is almost always related to some culture shock aspects (the first phases of the U-curve) - the unfamiliar conditions and the unknow language can create the sense of loss and disorientation. In our opinion, during this stage, the support of the receiving institution is of a special importance (consulations given by the ERASMUS coordinators, the support by the students' council of the university, etc.). At the same time, almost everobody (77 respondents) agreed or strongly agreed that Latvia is an apealing destination for travelling. Perhaps the most intriguing question of this group for us as researchers was the one related to the stereotype regarding local residents. The statement was formulated in the following way: 'Latvian people are not as introverted as I thought'. The answers were split almost evenly ( 26 repondents agreed and/or strongly agreed with the statement, that is, they 
were pleasantly surprised finding Latvians outgoing; 36 respondents stood by the stereotype, whilst 25 students didn't have a definite answer). In our opinion, these results emphasise the necessity of work to be accomplished before the mobility asignment, namely, students have to be informed about the lifestyle of the host country. Although it is virtually impossible to prepare thorough informative materials about each and every destination country, the problem could be solved by creating, for exmaple, Facebook discussion/interest groups in which students from the sending and receiving countries could share their experience and establish friendship already before coming to the country.

The next group consisting of four statements that were related to the general living conditions and students' vision to them (see Fig. 2).

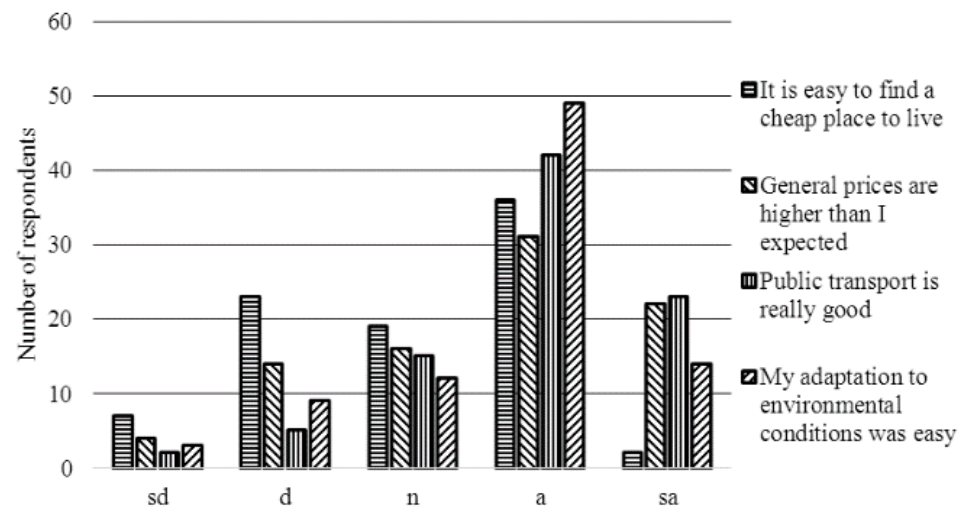

Fig. 2. Evaluation of living conditions (Source: authors' compilation)

The process of social-cultural adaptation, that is, the transition period from home environment to the unknown, the different one, also depends on students' living conditions (to rent an apartment together with friends, to live in the dormitory), readiness to adapt to the Nordic climate conditions (especially if students come from the south of Europe). Then here we have to mention the orientation problems in the city and public transportation structure. The answers to the first question in the group (see Figure 2) are distributed almost evenly; it means that students did not think to be too difficult to find relatively (of course, depending on the living standard in the country of origin) inexpensive living place. Also, students positively evaluated the ways of getting around in the city and they were not particularly bothered by rain, snow, coldish summer and so on. At the same time, 53 out of 87 respondents had been unpleasantly surprised by the level of general prices; they either agreed or strongly agreed to the statement number four in this group. This could mean that they did not have the exact information before travelling to Latvia. As majority of the students were from the EU countries, they could naturally assume that the price range would be approximately the same. This again brings forth the need for (1) thorough prior orientation and (2) prior virtual contacts with host university students. The next group of statements concerns students' leisure time activities (see Figure 3).

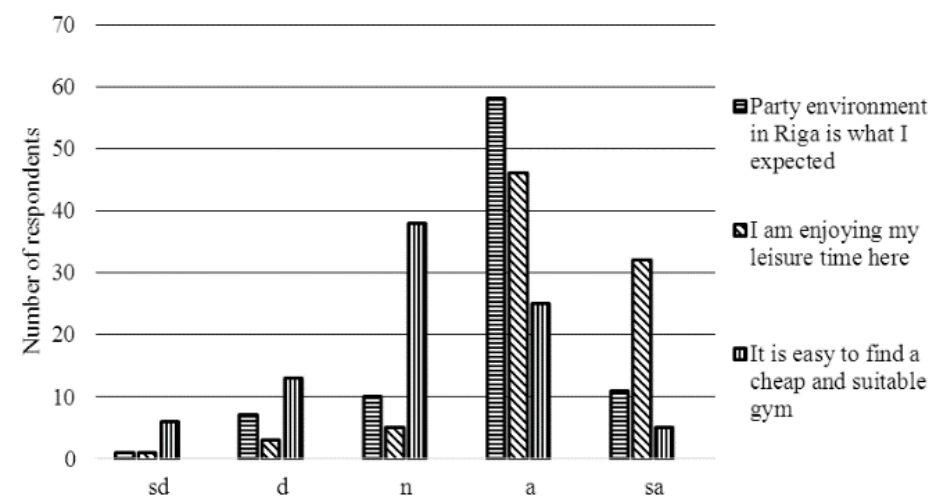

Figure 3. Students' evaluation of their leisure time activities (Source: authors' compilation) 
Without any doubt, students view their time spent in the foreign country as time for exploration of the party scene and entertainment possibilities. It is a natural part of their experience. Therefore, it is not a surprise that the statements received positive votes (69 of 87 respondents agreed or strongly agreed to first statement, and even more, i.e. 78, to the second one). The only disappointment was expressed regarding the inability to find the suitable gym or, rather to say, their attitude was mostly neutral. This could mean that they did not express any interest in this kind of activity or they found it too expensive. In this case, the solution could be organising international hiker/jogger groups.

Food culture and adjustment to the local cuisine is an important aspect. To close the gap, the host universities often organise national food festivals, potluck dinners and so on. Sometimes the comfort food of the native country is necessary to stay afloat in the foreign country. Figure 4 depicts ERASMUS students' attitude to the traditional dishes in Latvia.

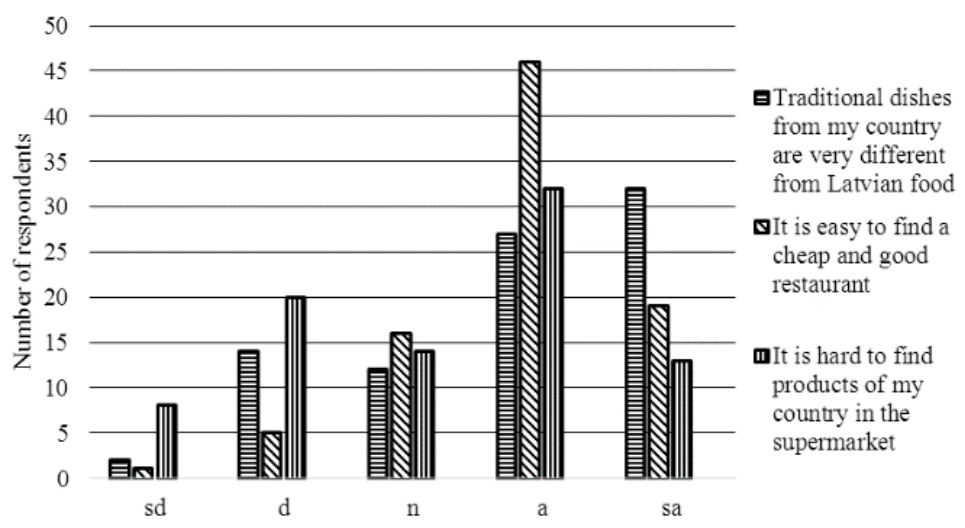

Fig. 4. Attitude to the local cuisine and dining traditions (Source: authors' compilation)

The answers to the first and to the third statement tends to be on the negative side, namely, 59 respondents agreed and strongly agreed that the traditional dishes are very different and 45 regretted inability to find the familiar products in the market or supermarket. Still most of them answered that it was not a problem to find a cheap and good restaurant (usually not serving their host country dishes).

The last group of statements touches upon very significant aspect communication with locals students and city residents (see Fig. 5).

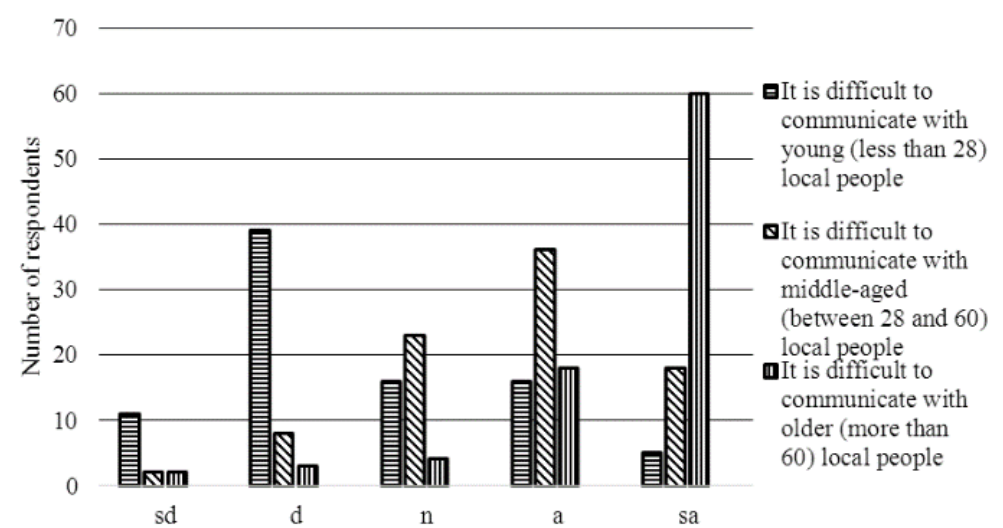

Fig. 5. Communication difficulties with local residents (Source: authors' compilation)

It is not surprising that there exists a direct negative correlation between age of the local residents and the knowledge of foreign language - the younger generation, in general, has no problems speaking lingua franca (English), whereas those aged 60 and more are less apt to have direct contacts with foreign students. The problem could be solved, at least partly, by pairing up international and local 
students, that is, some kind of mentoring. This approach is used by several universities in Latvia. However, if there is a compact group of foreign students, they can be satisfied with the intra-group communication. Then the question arises: should the local universities try to break up this circle and engage more in the host university students' life?

In order to see the situation from the different perspective, the authors of the present study conducted semi-structured interviews with the ERASMUS coordinators from three Riga universities. The questions concerned different social and cultural aspects of ERASMUS students' life. The interviews were taped, coded as A, B and C and analysed using the inductive thematic analysis that is, finding the themes relevant for the current topic. In sum, three main themes emerged in the interviews: (1) technical and organisational assistance by the receiving institution; (2) engagement in the local social and cultural activities; (3) students' prior awareness of local conditions and traditions.

According to all ERASMUS coordinators, the incoming students receive all necessary technical and organisational assistance - their prospective 'buddies' (students who would fulfil the role of some kind of personal assistant during all study period in Latvia) are picking them up at the airport. The representatives of the Students Council of the respective universities or volunteers help to overcome the daily difficulties (finding supermarket, explaining the system of public transportation, etc.). All coordinators admitted that the most difficult part of their job was the great amount of the paperwork.

The second common theme in all interviews was related to involving the ERASMUS students into the local (host university) cultural and social activities. All coordinators answered that their schools have organised field trips to beautiful places of Latvia and sometimes abroad, sporting and entertainment events. According to one of the coordinators: 'Yes, there are trips (usually once a month). For sport it is different because, for example, during this period it is difficult to organize something outside because of the weather'. Yet another coordinator admitted that the students' council of the university had an annual tradition - the international gastronomy month, where the students introduced their national dining traditions. This, of course, is possible in the universities that have a large number of foreign students.

The third theme that appeared in all three interviews concerned the problem of readiness of incoming students to adapt to the local social, economic, cultural and academic standards. In other words, many students upon arriving in Latvia exhibit obsolete stereotypes and prejudices. Although it is not always a case, still it seems that some prior practical training would be in place. Similarly, the local students, university staff and professors should be well prepared. The university responsibility would be, first, to work with every international student and, second, to prepare the teaching staff for working within the international environment. In order to accomplish the latter task, the school organises integration and culture training seminars for teaching staff and for those who are involved with international students on the daily basis.

In the end, all coordinators admitted that incoming ERASMUS students have brought to their schools valuable cultural diversity experience.

\section{Conclusions}

The purpose of the present study was to investigate the critical aspects of the ERASMUS students' cultural adaptation in Latvia. In order to reach it, the international team of researchers (consisting of the local university professor and three ERASMUS students from Spain and Italy) conducted the survey (the non-probability purposive sampling) and series of semi-structured interviews with the ERASMUS coordinators. There were two research questions: (1) What are the most problematic aspects of ERASMUS students' social-cultural adaptation in Latvia? (2) What are responsibilities of host universities in ensuring international students' cultural and social adaptation?

According to research data, the answer to the first question could be formulated as follows: the most problematic (critical) factors in the ERASMUS students' cultural and social adaptation Latvia were the lack of crucial information about the receiving country and the host universities. It does not mean that they arrive unprepared; still, they can hold some prejudices and stereotypes (of course, depending on their country of origin). They experience the subsequent stages of the culture shock (differences in 
lifestyle, food and dining traditions, difficulties in communication, etc.). In students' opinion, the Latvian people are largely perceived as being introverted and there exists the direct negative correlation between the age of the local residents and their ability to communicate in English. This set of problems could be solved by further developing the 'buddy' (or mentoring) system as well as by preparing informative materials about the country and the host university. In addition, establishing the Facebook discussion group in which the students could contact their Latvian counterparts before to the actual travelling to Latvia could solve at least some of the initial problems.

The university responsibility would be, first, to work with every international student and, second, to prepare the teaching staff for working within the international environment. In order to accomplish the latter task, the school organises integration and culture training seminars for teaching staff and for those who are involved with international students on the daily basis.

\section{References}

Archer, W., Davison, J. (2008). Graduate Employability: What do Employers Think and Want? London: The Council for Industry and Higher Education.

Altbach, P. G., Knight, J. (2007). The internationalisation of higher education: Motivations and realities. Journal of Studies in International Educational, (11), 290-305.

Bennett, M. J. (2004). Becoming Interculturally Competent. Towards Multiculturalism. A Reader in Multicultural Education. Newton, MA: Intercultural Resource Corporation, 62-77.

Bhandari, R., Blumenthal, P. (2011). Global Student Mobility and the Twenty- First Century Silk Road: National Trends and New Directions. International Students and Global Mobility in Higher Education National Trends and New Directions. New York: Palgrave Macmillan, 1-24.

Bochner, S. (2003). Culture Shock Due to Contact with Unfamiliar Cultures. Online Readings in Psychology and Culture, (8). [Accessed 25.08.2017] Available from Internet: https://core.ac.uk/download/pdf/10687087.pdf

Bracht, O., Engel, C., Janson, K., Over, A., Schomburg, H., Teichler, U. (2006). The Professional Value of ERASMUS Mobility. Kassel: International Centre for Higher Education Research.

Crossman, J. E., Clarke, M. (2010). International Experience and Graduate Employability: Stakeholder Perceptions on the Connection. Higher Education, (59), 599-613.

European Commission. (2014). The Erasmus Impact Study. Effects of Mobility on the Skills and Employability of Students and the Internationalisation of Higher Education Institutions. [Accessed 15.-8.2017] Available from Internet: $\quad$ http://ec.europa.eu/dgs/education_culture/repository/education/library/study/2014/erasmusimpact_en.pdf

European Commission. (2015). Erasmus. Facts, Figures \& Trends. The European Union support for student and staff exchanges and university cooperation in 2013-2014. [Accessed 15.08.2017] Available from Internet: http://ec.europa.eu/dgs/education_culture/repository/education/library/statistics/erasmus-plus-facts-igures_en.pdf

Furnham, A., Bochner, S. (1986). Culture Shock. London: Methuen.

Gaw, K. F. (2000). Reverse Culture Shock in Students Returning From Overseas. International Journal of Intercultural Relations, (24), 83-104.

Geeraert N., Demoulin S. (2013). Acculturative stress or resilience? A longitudinal multilevel analysis of sojourners' stress and self-esteem. Journal of Cross-Cultural Psychology, (44), 1239-1260.

Giuffré, L., Ratto, S. E. (2014). A New Paradigm in Higher Education: University Social Responsibility (USR). Journal of Education \& Human Development, (3/1), 231-238.

Grewal, R., Dearden, J. A., Lilien, G. L. (2008). The University Rankings Game: Modeling the Competition among Universities for Ranking. The American Statistician, (62), 232-237.

Gullahorn, J. T., Gullahorn, J. E. (1963). An Extension of the U-Curve Hypothesis. Journal of Social Issues, (19), 33-47.

Gürüz, K. (2008). Higher Education and International Student Mobility in the Global Knowledge Economy. Albany: State University of New York Press. 
Hawawini, G. (2016). The Internationalization of Higher Education and Business Schools. A Critical Review. Singapore: Springer Science+Business Media Singapore Pte Ltd.

Hofstede, G. (2001). Culture's Consequences: Comparing Values, Behaviors, Institutions, and Organizations Across Nations. Thousand Oaks, CA: Sage Publications.

Hofstede, G., Hofstede, G. J., Minkov, M. (2010). Cultures and Organizations. Software of the Mind. Intercultural Cooperation and Its Importance for Survival. New York, Chicago, San Francisco, Lisbon, London, Madrid, Mexico City, Milan, New Delhi, San Juan, Seoul, Singapore, Sydney, Toronto: McGraw-Hill.

International Student Mobility Charter. [Accessed 01.09.2017] Available from Internet: https://www.ieaa.org.au/documents/item/14

Knight, J. (2007). Internationalization: Concepts, Complexities and Challenges. International Handbook of Higher Education. Dordrecht, The Netherlands: Springer, 207-228.

Larsen, M. A. (2016). Internationalization of Higher Education. An Analysis through Spatial, Network, and Mobilities Theories. New York: Palgrave Macmillan.

Mendenhall, M. E. (1991). The U-Curve Adjustment Hypothesis Revisited: A Review and theoretical Framework. Journal of International Business Studies, (June), 225-247.

Oberg, K. (1960). Cultural Shock: Adjustment to New Cultural Environments. Practical Anthropology, (7), $177-$ 182.

Pedersen, E. R., Neighbors, C., Larimer, M. E., Lee, C. M. (2011). Measuring Sojourner Adjustment among American Students Studying Abroad. International Journal of Intercultural Relations, (35), 881-889.

Richardson, R., Munday, J. (2013). International Student Mobility Programs and Effects on Student Teachers' Perceptions and Beliefs about Education and Their Role as Future Educators. Universal Journal of Educational Research, (1), 240-246.

Studying and Training Abroad. Student Guidebook. (2015). Brussels: Erasmus Student Network AISBL.

Teichler, U. (2004). Temporary study abroad: The life of ERASMUS students. European Journal of Education,(39), 395-408.

Teichler, U. (2007). The Changing Role of Student Mobility. [Accessed 25.08.2017]. Available from Internet: https://www.researchgate.net/profile/Ulrich_Teichler/publication/242159121_The_Changing_Role_of_Student Mobility/links/542e9fff0cf277d58e8ecee0.pdf

Varghese, N. V. (2008). Globalization of higher Education and Cross-Border Student Mobility. Paris: IIEP.

Vevere, V. (2016). Globalization of Higher Education and University Social Responsibility. In 16th International Conference "Globalization and its Socio-Economic Consequences". Conference proceedings, 2362-2369.

Ward, C., Bochner, S., Furnham, A. (2001). The Psychology of Culture Shock. Hove: Routledge.

Wu, H., Garza, E., Guzman, N. (2015). International Student's Challenge and Adjustment to College. Education Research International. [Accessed 20.08.2017]. Available from Internet: https://www.hindawi.com/journals/edri/2015/202753/

Zhou, Y., Jindal-Snape, D., Topping, K., Todman, J. (2008). Theoretical Models f Culture Shock and Adaptation in International Students in Higher Education. Studies in Higher Education, (33), 63-75. 